\title{
MÚLTIPLOS OLHARES, MUITAS IMAGENS: O MANEJO DE PARQUES COM BASE NA COMPLEXIDADE SOCIAL
}

\author{
DOUGLAS DE SOUZA PIMENTEL \\ Universidade do Estado do Rio de Janeiro \\ Universidade Federal Fluminense \\ TERESA CRISTINA MAGRO \\ Universidade de São Paulo
}

\section{Introdução - O caminho do meio: novos olhares para a gestão de parques}

As Unidades de Conservação (UCs) representam um modelo muito utilizado como importante estratégia de gestão do território, regulando as dinâmicas de uso dos recursos e ocupação do espaço. O Sistema Nacional de Unidades de Conservação (SNUC) as organiza em dois grupos de categorias: as de proteção integral, dentre as quais estão os parques, e as de uso sustentável (Brasil, 2002). A sua aplicação não está livre de conflitos, que ocorrem em diferentes escalas.

A conservação ambiental configura-se como uma ciência essencialmente multidisciplinar (Primack; Rodrigues, 2007). No âmbito do conhecimento ecológico, os parques e outras Unidades de Conservação de proteção integral representam a aplicação prática da visão de preservação dos processos ecossistêmicos livres da interferência humana. Godoy (2000) considera que a criação do Parque Nacional de Yellowstone, em 1872, nos EUA, inaugurou um modelo que seria o resultado de uma ideologia e sociedade fundamentadas nesse pragmatismo científico. Portanto, há uma fundamentação filosófica para a criação e gestão de áreas protegidas, muito discutida na literatura, em que uma visão dicotômica fica evidente, quando se compara a argumentação de alguns autores expoentes nesse debate.

Diegues (2000, 2004), por exemplo, destaca que os parques têm se revelado inadequados para atingir os objetivos da conservação, além de 
representarem uma transposição do modelo americano para diferentes situações ambientais e culturais ao longo do globo. Essa visão resultaria em ilhas isoladas da realidade econômica e social. No entanto, Terborgh e Van Schaik (2002) rechaçam a ideia de os parques representarem um imperialismo americano e questionam se há algum mal na importação de valores culturais frente à importância da conservação do patrimônio ambiental. Esses e outros autores consideram os parques como a pedra fundamental das estratégias de conservação (Dourojeanni; Pádua, 2007; Milano, 2002).

Assim, os parques representam um modelo icônico de conservação cuja aplicação não está livre de críticas. Essas críticas se relacionam fundamentalmente ao cerne ideológico que substanciou a argumentação sobre a exclusão de pessoas dessas áreas protegidas, o que se observou em um contexto histórico e, de certa maneira, representa um passivo à sua imagem perante a sociedade, bem como à falha dos órgãos gestores, geralmente estatais, na sua administração e em seu manejo.

Ora, a reserva de áreas para a conservação regulamenta espaços construídos socialmente, o que aumenta a complexidade das interações, que vão além das ecológicas. Assim, o foco restrito da Biologia não tem amplitude suficiente para propor uma forma de manejo que seja sensível a essas novas variáveis introduzidas. O parque está amalgamado a um ambiente social, nas suas esferas política, territorial, administrativa e simbólica. Há a necessidade de uma postura interdisciplinar, que não pode ser alcançada por posições extremas e pelo diálogo rarefeito do radicalismo. Nesse sentido, o artigo objetiva analisar os pontos de congruência entre essas visões diversas, tendo como norte a sua aplicação no manejo mais eficiente de parques.

\section{Motivação, método e organização do artigo}

O presente texto resulta de uma análise teórico-conceitual sobre o processo de inserção social dos parques, tendo como base o extenso debate de diferentes autores, com diferentes formações e pontos de vista, sobre as relações entre os parques e as pessoas. Assim, apesar de haver o risco de perda da sua riqueza de detalhes, novos olhares podem contribuir para que se avance academicamente nessa discussão, bem como, pragmaticamente, na gestão dos parques e de outras áreas protegidas. Para tal, o texto parte da discussão conceitual sobre o espaço geográfico, suas dimensões diversas e os possíveis paralelismos com o conceito de parques e a sua 
gestão. Em seguida, reforça a ideia de que a administração dessas UCs sofre com a natureza multiescalar dos procedimentos de gestão, bem como com os diversos valores atribuídos aos espaços naturais protegidos. Dessa maneira, a construção dos temas aqui apresentados ratifica a necessidade de conhecer o conjunto de percepções sobre o parque e sua administração como forma de abordar a complexidade das suas relações com a sociedade.

\section{O olhar epistêmico da Geografia}

As discussões sobre o espaço ocorrem no campo da Geografia, em que operam os conceitos necessários para o entendimento das relações humanas com a superfície terrestre (Corrêa, 1995). Assim, as diferentes identidades atribuídas ao espaço servem para a re-introdução desse conceito na pesquisa ecológica (Little, 1999). Esse também é o locus de diferentes práticas, alicerçadas por padrões culturais para a administração e o controle das singularidades, muitas vezes impostas à sua organização, como no caso dos parques.

Nesse sentido, o espaço pode ser considerado no âmbito de sua existência física e de sua essência subjetiva, relacionada à forma como as pessoas o percebem, pelas estruturas e pelo universo das imagens percebidas e codificadas com diferentes significados (Moreira, 2002). Logo, conceber um parque como o mero espaço da perpetuação dos processos ecológicos representa uma visão de mundo fragmentada e de difícil utilidade como um modelo para a compreensão dos fenômenos operantes (Röper, 1999). Porém, a polissemia do conceito de espaço torna difícil a sua aplicação no manejo de parques.

Em adendo, esse aumento de complexidade para a gestão que considera as interações sociais já foi usado como argumento contrário às Unidades de Conservação de uso sustentável (Dourojeanni; Pádua, 2007). Esses autores chegam a concluir que a "única razão para se estabelecer áreas naturais protegidas é resguardá-las contra o ser humano. Não tem lógica fazer áreas protegidas ou Unidades de Conservação para que nelas o homem explore a natureza..." (p. 258). Essa visão remete a uma certa resistência conceitual de se buscar a compreensão dos fenômenos socioambientais relacionados ao manejo de parques, o que o presente texto considera condição fundamental para a conservação.

Muito se fala de uma abordagem regional para a administração de parques. A região compreende um determinado território cuja área é usada 
como unidade de gestão administrativa (Pires; Santos; Pires, 2003). Como os parques podem ser entendidos como tal, essas áreas, bem como o seu entorno, poderiam ser mais bem compreendidas sob o foco conceitual da região. Essa visão ampla para a gestão de parques é vislumbrada no estabelecimento de sua zona de amortecimento. Porém, a sua aplicação ainda é emperrada pela difícil integração das diferentes esferas políticoadministrativas.

De acordo com Paasi (2002), a identidade de uma região é parte do processo de institucionalização do espaço. Röper (2000), baseada nesse autor, faz uma proposta interessante para o desenvolvimento de uma abordagem relacional entre sociedade e áreas protegidas. A autora considera que a criação de Unidades de Conservação pode ser enfocada sob esse processo. Assim, para que a gestão seja efetiva, o manejo deve se dar sob três eixos conceituais: a) a forma institucional que se responsabiliza pela perpetuação e o controle do espaço; b) a forma territorial estabelecida juridicamente e, c) a forma simbólica relacionada com a percepção e ação das pessoas sobre o espaço. Portanto, a criação e gestão dessas áreas protegidas não deveriam ser compreendidas como um resultado de argumentação técnica e científica engessada em um arcabouço legal, mas sim como um processo resultante de um cenário em que se debatem interesses variados de uma série de atores em conflito (Ferreira, et al. 2007; Pimentel; Souza; Magro, 2009; Röper, 1999).

Nesse sentido, o manejo eficiente de um parque necessita da participação da sociedade na construção dessa identidade do espaço público, com o objetivo de conservar o patrimônio ambiental comum, resguardando-o de interesses privados. No entanto, em bases cotidianas, os administradores têm que lidar com os aspectos ecológicos do manejo da biodiversidade, com os interesses das comunidades locais e com a falta de recursos (Ormsby; Kaplin, 2005). A procura pela base do consenso e seus limites (Rodrigues, 2001) permite o estabelecimento de pontos de interesse convergentes para a execução de um manejo que minimize a tensão entre as partes, bem como estimule um processo de monitoramento dessa relação (Bridgewater, 2002). Fica evidente que essa não é uma tarefa fácil, ainda dificultada por variáveis como realidades locais diversas e a capacidade do gestor em lidar com os inevitáveis conflitos. No entanto, no caso das UCs de proteção integral, a lei estabelece como princípio o uso indireto dos recursos para a conservação ambiental. Assim, sobre esse alicerce crescem as fronteiras da discussão e, como se parte da premissa do ambiente ecologicamente equilibrado, considerado um bem comum a todos, a 
conservação ambiental também representa um importante papel social dos parques.

É importante considerar ainda que os parques são instituições que medeiam as relações socioambientais. Logo, a efetiva conservação deve ser alcançada no desenvolvimento de um processo em que a UC evolua de uma estrutura estranha às comunidades a um conjunto de regras e dispositivos reguladores que resultam de um pacto entre os diferentes atores sociais. A Educação Ambiental tem sido apontada como um instrumento para disponibilizar informações, compartilhar percepções e ampliar o diálogo e as ações conjuntas para fomento da atuação democrática e qualificada dos cidadãos nas discussões sobre os parques, especificamente nos conselhos gestores. Sob esse prisma, os conflitos inerentes ao processo são explicitados e as discussões são aperfeiçoadas pela melhor inserção dos atores envolvidos. Essa ampliação qualitativa provoca mudanças positivas nas relações entre a administração do parque e a sociedade (Ibama, 2002; Ibase, 2006; Loureiro; Azaziel; Franca, 2003). A abordagem da conservação, considerando esse sistema interativo, seria melhor do que o foco na criação e no reforço das regras (Agrawal; Gibson, 1999). Nessa perspectiva, o presente texto considera que o Conselho Gestor do parque ganha importância para efetivar o manejo que abrange a complexidade das relações socioambientais com a UC, pois os problemas e as soluções na administração dos parques emanam de diferentes interrelações, que precisam ser criticamente compreendidas pelos gestores e pelas comunidades locais.

De maneira diferente, o conceito de ecorregião está relacionado às áreas com presença de espécies importantes para a conservação, onde as atividades humanas devem ser reduzidas (Pires; Santos; Pires, 2003), o que ratifica uma visão de conservação pouco aberta às relações socioambientais que influenciam a gestão de um parque. Como contraponto, outra abordagem para a gestão ambiental, a ecossistêmica, tenta promover o conceito integrador de biorregião, território cujos limites não são definidos por fronteiras políticas, e sim por limites geográficos de comunidades humanas e ecossistemas (Fall, 2003). Nessa visão, o desenvolvimento regional e a produção de bens e serviços só podem se processar de maneira sustentável se também forem consideradas as variáveis relativas ao funcionamento dos sistemas ecológicos e o contexto local. Entretanto, segundo Fall (2003), a complexidade da situação destrói a lógica interna do sistema de fragmentação do espaço e as fronteiras passam a se fluidificar frente às diferentes abordagens metodológicas. No caso dos parques, há um descompasso na aplicação das diferentes dimensões do espaço na sua 
gestão, que é substancialmente dificultada pelas três instâncias da administração pública englobadas na escala regional.

Pode-se exemplificar esse problema com o Programa da UNESCO Homem e Biosfera ( $\mathrm{MaB}$ - Man and the Biosphere), que propõe um planejamento integrado para as Reservas da Biosfera. A lógica do sistema refere-se ao zoneamento de uma região com a designação de uma UC, geralmente de uso mais restritivo, como área núcleo para a preservação. Essas reservas deveriam cumprir, portanto, três funções independentes: a conservação; o desenvolvimento sustentável; e a construção de uma base logística para pesquisa, monitoramento, formação e educação (Barbault, 2006). Entretanto, o zoneamento efetivo tem-se mostrado difícil de ser alcançado, pois além de abranger diferentes instâncias de poder, geralmente os ecossistemas mais ameaçados estão em regiões densamente habitadas, e o estabelecimento de áreas núcleo comumente envolve o deslocamento de pessoas com a capacidade potencial de geração de conflitos (Alpert, 1995). Além disso, segundo Pedlowski (1999), programas regionais geralmente perdem o foco na aplicação de recursos e apresentam conflitos de jurisdição e cooperação entre os órgãos estatais.

$\mathrm{O}$ conceito de território também vem sendo empregado nas discussões sobre áreas protegidas. De maneira ampla, pode ser compreendido como um campo de forças emanado de uma rede de relações sociais projetadas no espaço, que definem limites e alteridades (Souza, 1995. p. 78). Assim, esse conceito também assume características polissêmicas quando visto sob o ponto de vista simbólico, como descreve Rodrigues (2001) para a Ilha do Cardoso. Isto é, o parque é apenas um dos territórios sobrepostos no local. Nesse âmbito, a exclusividade do exercício do poder heterônomo sobre o território também é questionada frente à possibilidade de coletividades ganharem autonomia para uma gestão socialmente justa do seu espaço vivido (Rodrigues, 2001; Souza, 1995).

Segundo Lutzenhiser (2002) e Görg (2004), o olhar sobre as relações de poder pode permitir a compreensão dos fenômenos resultantes da interação entre os seres humanos e o ambiente. Dessa maneira, o último, quando analisa as diferentes dimensões do conceito de biodiversidade, propõe que os objetos naturais também são construídos por relações sociais. Assim, para serem compreendidos, precisam de uma abordagem mais ampla do que o foco restrito da Ecologia. Essa argumentação, apesar de se sustentar em outra dimensão conceitual do espaço geográfico, também corrobora com a necessidade de um manejo mais sensível à complexidade das relações entre o parque e a sociedade. 
Como já foi relatado, o conceito de parque carrega consigo a sustentação fílosófica de um controle mais rígido do território. Como grande parte do processo histórico que resultou no estabelecimento dos parques no Brasil se deu sob a égide do regime militar, Medeiros (2006) e Medeiros, Irving e Garay (2006) acreditam que, pelo menos nesse período, as UCs representaram uma forma de controle geopolítico do espaço territorial brasileiro. Abakerli (2001) considera ainda que o discurso da manutenção da soberania e da segurança nacional e a pressão de organizações internacionais, como o Banco Mundial e o Banco Interamericano de Desenvolvimento, foram os direcionadores principais na implementação da política de áreas protegidas no país. Nesse sentido, aparecem as dificuldades na aplicação da gestão participativa nos parques, onde a atuação comunitária é incentivada no discurso, mas pode estar esbarrando na resistência das diferentes esferas do Estado em efetivamente conceder a autonomia decisória. Como afirma Röper (1999), a necessidade de participação popular na criação de UCs tornou-se um lugar comum em diferentes abordagens, mesmo as ecológicas. No entanto, ficam evidentes as dificuldades inerentes ao processo de implantação de um modelo de proteção integral que carrega métodos autoritários em seu bojo.

A questão da participação também é debatida por Rodrigues (2001). $\mathrm{Na}$ sua avaliação sobre o comitê gestor do Parque Estadual da Ilha do Cardoso, no litoral de São Paulo, a autora concluiu que o sucesso das ações ficou condicionado ao respeito e à abertura efetiva aos diferentes atores. A mediação do diretor do parque na época teria sido importante na medida em que ele acompanhou o processo de planejamento desde o início e franqueou ao comitê gestor o poder decisório. Essa observação reflete o melhor e o pior na gestão dos parques, pois, enquanto o conceito de participação ganha a amplitude de exploração dos problemas de manejo (Stringer et al., 2006) - além de fugir de um pensamento linear, muitas vezes presente em diferentes escalas administrativas que não consideram o balanço dos múltiplos interesses, conhecimentos, preferências e valores (Lynam et al., 2007) -, a gestão é fragilizada pelo reconhecimento da temporalidade desse poder. Logo, reforça-se a necessidade de uma diretriz política mais clara dos órgãos gestores para incentivar uma participação mais consciente e duradoura das pessoas na administração dos parques. $\mathrm{Na}$ produção desse território são atribuídos valores mensuráveis e não mensuráveis que impulsionam a ação conservacionista, importante para a sociedade em um dado momento histórico (Vallejo, 2002). As relações de poder, sendo evidenciadas pela habilidade de cada ator em influenciar e 
controlar sua própria interação e a de outros atores com o ambiente, sob a complexidade dos interesses específicos.

Assim, a ótica dos conflitos relacionados à implantação dos parques permitiu a Ferreira (2004) concluir que o embate de atores sociais é determinante para o sucesso de políticas ambientais. Porém, quando o debate acadêmico apoia-se em posições ideológicas radicais, sem dar subsídios à construção de alternativas, há dificuldades em sua aplicação prática na administração. A pesquisa sobre essas interações poderia ajudar na compreensão da natureza e da dinâmica desses conflitos, contribuindo, assim, com a gestão dos parques (Abakerly, 2001).

Considerando ainda que, na conceituação do espaço, a singularidade do humano também deve ser observada, os significados subjetivos atribuídos aos lugares evidenciam o modo de ver o mundo sob influência das crenças individuais (Holzer, 1999). Assim, o lugar pode ser visto como o espaço que possui um espírito, assumindo um sentido que se torna coerente pela apreciação sensorial a partir de uma longa vivência e pela experiência. Ele engloba a percepção e a emoção em um gradiente que gera diferenças de posturas frente ao espaço, que acaba por se configurar como um campo de representações simbólicas (Tuan, 1983). O lugar passa a ser também o espaço da afetividade (Corrêa, 1995), ligando a pessoa ao ambiente físico, no que Tuan, (1980) chama de topofilia, um conceito que reúne o simbólico e o concreto das experiências pessoais. Nesse sentido, discute-se agora como essa perspectiva pode contribuir para os debates sobre os parques e sua gestão.

Godoy (2000) considera que, apesar dos diferentes argumentos historicamente empregados, o objetivo primordial do processo de isolamento de lugares é a proteção dos recursos naturais. Em comum também parece ser a crença da predestinação de lugares, seja por Deus, seja pelo estabelecimento de valores pragmáticos da ciência. West; Igoe e Brockington (2006) acreditam que haja lacunas na literatura sobre as complexidades da produção social do espaço. Faltam discussões que tratem da relação entre os parques e a criação de lugares. Considera-se aqui que o conceito de lugar, aliado ao de parque, transforma o espaço heterogêneo e instável em uma natureza mais homogênea e previsível. No entanto, o reconhecimento dos parques como um conjunto de processos passíveis de serem explicitados apenas pela Ecologia cria um espaço autônomo cuja existência pretende ser independente das interações sociais da qual emerge, gerando um conflito travado em duas dimensões diferentes, a individual e a social. Logo, essas últimas perspectivas devem ser conhecidas pela 
pesquisa socioambiental para que o manejo possa se dar sobre bases mais próximas da realidade social na qual o parque está inserido.

Outro conceito relacionado à concepção social do espaço também pode ser empregado nas discussões sobre os parques, pois à paisagem, que não está livre da subjetividade humana, atribuem-se diferentes valores culturais, que filtram a realidade para o observador (Maximiano, 2004). Esse conceito, associado à estética, foi utilizado como argumento para a criação do Parque Nacional de Yellowstone e até hoje se encontra entre os princípios básicos dos parques brasileiros: "a preservação de ecossistemas naturais de grande relevância ecológica e beleza cênica" (Brasil, 2002. p. 16). Assim, apesar de existirem algumas críticas pontuais em torno desse objetivo específico para a criação dessa categoria de UC, geralmente paisagens com alto valor cênico são ao mesmo tempo ecossistemas de relevância ecológica. Portanto, não há razão para a continuidade desse tipo de argumentação para diminuir o valor da criação de parques. Não obstante é importante ressaltar que a paisagem engloba constructos resultantes de um processo interativo entre a sociedade e o ambiente (Meinig, 2002, Gröning, 2004), cujo conhecimento é importante para a gestão de parques, pois a paisagem também representa um campo de significação cultural (Cabral; Buss, 2002).

Nessa linha argumentativa também se desenvolve o conceito de paisagem biocultural, segundo o qual o entendimento da sustentabilidade dos sistemas ecológicos somente poderia ser alcançado pela compreensão dos aspectos culturais da sociedade. Sob essa abordagem, a percepção, os valores, as convenções culturais, as concepções da natureza e a aparência das paisagens que comunicam valores culturais seriam importantes para a compreensão da sua dinâmica no espaço e no tempo (Bertolas, 1998, Bridgewater, 2002).

Cabral e Buss (2002) destacam que a institucionalização da paisagem em um parque representa uma "expressão normativa extremamente elaborada desse processo" (p. 60). Além disso, a paisagem é contemplada em um único ponto e congrega diferentes elementos que não necessariamente fazem parte dos parques, como as construções humanas de um bairro próximo. Os visitantes muitas vezes admiram as estruturas externas ao parque, pois, mais uma vez, as fronteiras são arbitrárias e não percebidas pelas pessoas. Se não há programas de interpretação ambiental, o parque pode se tornar invisível aos olhos de quem o observa, ou tão intrinsecamente enredado nas estruturas paisagísticas que tornaria difícil o discernimento dos motivos que levaram à delimitação do espaço como uma 
área protegida. Os conceitos de paisagem são variáveis de acordo com quem os emprega, e a delimitação de parques, de certa maneira, tenta domá-la, ao impor artificialmente uma heterogeneidade mono-escalar ao espaço e reduzi-lo às suas dimensões ecológicas (Pimentel; Souza; Magro, 2009).

Ainda segundo Fall (2003), a implementação de áreas protegidas depende de argumentos que justifiquem o estabelecimento de fronteiras. Esse processo embute falhas que são refletidas na criação e posterior administração do espaço. Enquanto as fronteiras são definidas como limites físicos inerentes à paisagem, elas também podem ser tratadas como um fenômeno social. Logo, o planejamento ambiental depende do desenvolvimento de um modelo que vença os paradigmas para encontrar uma unidade de gestão viável ecológica e socialmente.

Ora, os parques são construções sociais, políticas e históricas, tanto conceitualmente quanto na sua existência física no espaço. Assim, considerando ainda que as interações ambientais não se restringem apenas às suas variáveis ecológicas, uma vez que as atividades humanas relacionam-se intrinsecamente aos processos de degradação e conservação da natureza, a compreensão das relações entre a sociedade e essas áreas protegidas também traz contribuições importantes para o seu manejo. Portanto, pode-se destacar que as relações ecológicas são tão importantes para a conservação quanto o entendimento da constituição do espaço em um parque como um processo mutável em que se observa um resultado estrutural emanado das relações de poder - que influenciam sua história e gestão -, das subjetividades afetivas e das limitações e decisões administrativas.

\section{O olhar fragmentado em diferentes escalas}

A escala tem uma definição matemática bem delineada, que estabelece parâmetros para alterar as magnitudes reais e levá-las a um plano dimensional manejável. De maneira mais abrangente, pode-se considerar que mudanças de escala são mudanças no nível de análise e conceituação, apresentando especial aplicação nas questões da conservação. Assim, a explicação dos fenômenos somente se encontra no entendimento de escalas cruzadas, com dimensões e dinâmicas distintas (Reboratti, 2001). 
Segundo Little (1999), existe uma simetria epistemológica das questões ambientais que deve ser continuamente confrontada com a assimetria ontológica das interações operantes nos sistemas socioambientais. Essa visão de cima para baixo permite apenas uma observação superficial dos fenômenos. Assim, a análise nas diferentes escalas revela as articulações internas, os agentes operacionalmente significativos e as relações entre as pessoas e seus ambientes. Portanto, é essencial que o conhecimento sobre as inter-relações mantidas em diferentes escalas seja aplicado na gestão de parques. No entanto, há indagações sobre se o foco localizado sobre essa categoria de manejo dificultaria o entendimento das complexas interações sociais mantidas com a UC (Schwartzman; Nepstad; Moreira, 2000).

Bensusan (2006), tratando amplamente das UCs, acredita que a sua administração envolve diferentes escalas, que geralmente transcendem espacial e temporalmente a área protegida. Porém, a ideia tradicional de manejo baseado no comando e controle de órgãos centralizadores assentase sobre um pensamento linear de causa e efeito, para torná-lo mais previsível e controlável. Logo, a visão em escalas estanques afeta a ligação entre essas instituições e os processos socioambientais (Berkes, 2004). Conclui-se que não pode haver uma única escala para o manejo de parques. Nesse sentido, o conselho gestor assume grande importância, pois representa uma ponte de interligação entre essas diferentes escalas administrativas, amplificando a fluência entre as deliberações locais e as decisões administrativas do órgão gestor.

\section{Olhar e ver - influência recíproca entre percepção, valores e representações sociais}

A percepção do ambiente acontece pela interação dos estímulos sensoriais e pela estruturação cognitiva da informação. Engloba, portanto, o aparato físico dos sentidos e o olhar subjetivo da mente. Ou seja, a percepção é a maneira como olhamos o mundo e como os valores são projetados sobre ele. A percepção também carrega um forte componente cultural, pois depende de crenças, experiências, tradições, ideias e contextos socioeconômicos (Tuan, 1980, 1983; Younés; Garay, 2006). Os valores são formados pelo processo social do diálogo sob um prisma histórico, cultural e geográfico. Eles são constituídos e informados por julgamentos morais e éticos que acabam por criar prioridades de ideias e um sistema de crenças. Estes moldam o comportamento das pessoas e 
podem ser caracterizados como uma postura cultural básica (Tuan, 1980, 1983; O’Brien, 2003; Wade-Benzoni et al., 2007).

Os sistemas de valores também determinam como as pessoas veem a natureza. Eles compreendem uma escala que vai do valor intrínseco da natureza à visão de que tudo existe para uso humano. Todos esses aspectos determinam a sua grande diversidade, porém, nem sempre são considerados para se alcançar a conservação da biodiversidade em áreas protegidas (Brunckhorst, 2002). Observa-se que os parques tornam-se espaços mais conceituais e assumem um referencial de natureza primitiva, no gradiente em que a sociedade humana encontra-se cada vez mais afastada em direção ao outro extremo, ao espaço tecnologicamente transformado (Watson, 2000; Watson; Landres, 1999). Esses representam a maneira em que muitas pessoas vivenciam o ambiente natural. Logo, têm que ser analisados sob o prisma da construção social da natureza e de sua materialização (West; Igoe; Brockington, 2006).

Infield (2001) argumenta que as pessoas vivem imersas em um ambiente pleno de significados simbológicos. Logo, indivíduos diferentes percebem a natureza por meio de um conjunto de valores que influenciam sua maneira de interpretá-la. Assim, o conhecimento desses valores mutáveis e subjetivos por parte dos gestores permite o desenvolvimento de um pensamento mais flexível sobre o manejo de parques. Trudgill (2001) acredita que conhecer os valores subjetivos democratiza o debate da conservação, porém as tensões com as pessoas advêm quando os parques são manejados em termos de valores científicos postulados por experts.

Segundo O'Brien (2003), existe uma tendência no planejamento ambiental à quantificação dos fenômenos sociais e ecológicos, em detrimento da atenção às vidas privadas e às experiências subjetivas. No entanto, a compreensão de uma determinada ação social depende do olhar sobre os significados que a constituem e da busca das motivações para as pessoas agirem de certa maneira. Para tal, é necessária uma rede conceitual nova para o estudo das interações entre os grupos sociais e o ambiente, e a compreensão dos valores certamente representa uma importante contribuição. Porém, o grande número e a diversidade dos valores relacionados às questões ambientais os tornam de difícil incorporação no processo de tomada de decisões, o que remete, mais uma vez, ao aumento de complexidade na gestão dos parques e explica, pelo menos parcialmente, a resistência em considerá-los.

Wagner (1996) acredita que o sistema de valores, além daqueles baseados primordialmente na Ecologia, estabelece um quadro de referência 
importante para a conservação. Angermeier (2000) destaca ainda que as questões ambientais não se referem apenas a efeitos antropogênicos indesejáveis, mas também à natureza que a sociedade quer. Assim, como as políticas são baseadas em valores, eles acabam por influenciar a conservação mais do que o conhecimento biológico. Nesse âmbito, a gestão de áreas protegidas também é, reciprocamente, uma expressão cultural mutável no tempo (Bridgewater, 2002).

Jepson e Canney (2001) consideram a conservação como um movimento social. Como ela também engloba o estabelecimento de prioridades espaciais para a reserva de áreas, também deve ser baseada em valores. Nesse sentido, as atividades de conservação mantêm e desenvolvem valores sobre as relações entre a sociedade e o ambiente. Além disso, os valores, que reciprocamente definem e são definidos pela importância da conservação ambiental, auxiliam na manutenção do apelo público e resguardam a conservação de se tornar uma apropriação científica abstrata. Finalmente, também aumentam a transparência das estratégias e políticas de conservação da biodiversidade para o público. Outra questão relevante é que alterações ambientais podem ser percebidas como positivas ou negativas por grupos distintos, que possuem percepções e valores específicos sobre o ambiente.

Há uma forte ligação entre as pessoas e os parques - também construída pela experiência e pelo contato com essas áreas (Ryan, 2005). Tuan (1980) acredita que os valores construídos pela percepção do lugar têm mais poder em criar uma postura crítica no indivíduo. Isso tem conotações tanto positivas (atitudes de defesa) quanto negativas (antagonismo). O mesmo não acontece com o visitante, devido ao seu olhar superficial, carregado de valores estéticos. Assim, esse conceito evidencia uma aparente contradição da conservação em parques, pois essas áreas protegidas mudam as relações do lugar com as pessoas mais propensas a defendê-lo. Já os planejadores aplicam modelos que produzem pouca compreensão sobre as experiências subjetivas (Tuan, 1983).

A sensibilidade ambiental, portanto, representa um produto e um processo de re-elaboração de valores sociais e individuais (Gerhardt; Almeida, 2005). Não obstante, esses valores e conjunto de percepções representam uma parte do patrimônio cultural dos grupos sociais que se relacionam com áreas protegidas. No entanto, como o presente texto apresenta olhares alternativos e também complementares para o manejo de parques, amplifica-se a importância da compreensão e do respeito a esses parâmetros culturais. 
A teoria das representações sociais procura dar uma sustentação teórica na ampliação da visão da mera identificação de valores e crenças estanques, que surgem das experiências individuais e do processamento das informações por estruturas cognitivas, para a da formação de um sistema interativo dessas ideias, que resultam em atitudes em relação ao ambiente. Para a sua compreensão, baseia-se em diferentes métodos das ciências sociais (Bauer; Gaskell, 1999; Castro, 2003; Peluso, 2003). Para tal, há a necessidade de pesquisa multimetodológica que evidencie as relações das pessoas com os parques e a identificação dos fatores que prejudicam ou baseiam a conservação (Ormsby; Kaplin, 2005). Também importante é classificar as semelhanças e diferenças entre os conceitos de atitudes e crenças, para alargar o diálogo entre as ciências e propor novas questões sobre as representações do mundo, que dão sentido ao comportamento humano e legitimam a construção de um espaço de interlocução com os demais campos sociais (Castro, 2003; Gerhardt; Almeida, 2005). Segundo Peluso (2003), as representações sociais permitem a construção de uma ponte entre a sociedade e o indivíduo, pois procuram o sujeito sob o foco dos processos sociais mais amplos. Logo, essas representações, que são o locus de interseção entre meio, atividades e sujeitos, são incorporadas à comunicação e compartilhadas pela linguagem. Além disso, a teoria engloba um método de pesquisa que sustenta diferentes discussões sobre como ocorre a apropriação do espaço. No entanto, a variedade de métodos pode gerar uma fragilidade conceitual (Bauer; Gaskell, 1999). Assim, os parques configuram-se como um ponto de convergência das relações entre sociedade e natureza, e o processo de construção do conhecimento acadêmico sobre essas interações sociais e subjetivas pode contribuir para o desenvolvimento de metodologias passíveis de serem aplicadas para a compreensão de outras questões socioambientais.

\section{Considerações finais}

A visão técnico-científica da Ecologia prevaleceu no conceito de parques e possui vital importância na manutenção da biodiversidade ao longo da história da conservação no Brasil. No entanto, essa abordagem criou problemas com as pessoas, ao impor uma fragmentação do espaço e algumas mudanças na forma de seu uso, cujos propósitos são mal compreendidos pelo senso comum. Nesse âmbito, o ganho de importância da visão social e humana para o manejo de parques tende a minimizar essa 
lacuna. Porém, algumas características desse processo emperram essa união: a polarizaçã̃o entre as ciências sociais e naturais, os problemas epistemológicos relacionados ao conceito de espaço geográfico, a dificuldade de se lidar com sistemas complexos devido ao número de variáveis envolvidas, as diferentes escalas em que a abordagem pode ser realizada e a diversidade de situações particulares que podem se desenvolver. Todos esses aspectos fazem com que essa nova equação, em que as variáveis sociais tenham o mesmo peso que as ecológicas, seja facilmente proposta, porém arduamente alcançada. Nesse contexto, diversos questionamentos podem ser levantados sobre a busca de padrões gerais para a administração em detrimento das especificidades locais, a efetividade de processos participativos frente à legislação que limita o poder decisório, a compreensão social da necessidade de conservação em uma sociedade dominada pelo pragmatismo econômico, entre outros.

Nesse sentido, a compreensão do processo de construção da identidade na institucionalização de um espaço regional em um parque permite abranger a polissemia conceitual do espaço geográfico ao considerar as diferentes formas da UC, que acabam por estabelecer os parâmetros sociais básicos para a gestão, como as questões fundiárias, políticas e legais associadas à percepção dos grupos sociais sobre o parque e seu manejo.

Com essa amplitude, vislumbra-se o cenário em que diferentes interesses são expostos. Obviamente, a resultante desse encontro de forças também é direcionada pelo arcabouço legal que sustenta a conservação em parques, bem como pela administração centralizada, geralmente em uma escala diferente daquela do gestor, que está mais próximo das demandas locais. Porém alternativas podem aparecer quando se busca a real inserção da área protegida na realidade social.

Assim, o conhecimento sobre o conjunto de representações da sociedade sobre os parques e sua administração também se configura como um componente importante da conservação, pois pode subsidiar o gestor com informações para lidar com os conflitos inerentes à criação de parques e relacionados à realidade local. Espera-se que a crítica ao modelo de administração vigente gere gradativamente uma nova forma de gestão que tenha como princípio a compreensão de que tanto os fenômenos sociais quanto os ecológicos têm grande importância na conservação da biodiversidade. 


\section{MÚLTIPLOS OLHARES, MUITAS IMAGENS: O MANEJO DE PARQUES COM BASE NA COMPLEXIDADE SOCIAL}

Resumo: Os parques são Unidades de Conservação que representam uma estratégia de gestão do território, regulando as dinâmicas de uso dos recursos e ocupação do espaço. Esse assume diferentes identidades, que aumentam a complexidade da gestão dos parques, pois podem ser percebidos sob o foco de diferentes olhares, em múltiplas escalas e valores. $\mathrm{O}$ presente artigo objetiva realizar uma análise teórico-conceitual sobre o processo de inserção social dos parques, tendo como base o extenso debate de diferentes autores, com distintas formações e pontos de vista, sobre as relações entre os parques e as pessoas. Para tal, o texto parte da discussão conceitual sobre o espaço geográfico, suas dimensões diversas e os possíveis paralelismos com o conceito de parques. Argumenta-se que a constituição do espaço em um parque é um processo mutável emanado das relações de poder, que influenciam sua história e gestão, das subjetividades afetivas e das limitações e decisões administrativas. Em seguida, reforça-se a ideia de que a gestão dessas UCs sofre com a natureza multiescalar dos problemas, bem como com os diversos valores atribuídos aos espaços naturais protegidos. Nesse sentido, o conselho gestor de um parque assume grande importância, pois representa uma ponte de interligação entre essas diferentes escalas administrativas. Dessa maneira, ratifica-se a necessidade de conhecer o conjunto de percepções sobre o parque e sua administração como forma de abordar a complexidade das suas relações com a sociedade. Conclui-se que essa visão ampliada é importante para a conservação, pois subsidia um manejo que considera as dimensões humanas relacionadas aos parques.

Palavras-chave: parques; unidades de conservação; institucionalização do espaço; manejo.

\section{MULTIPLE LOOKING, MANY IMAGES: PARK'S MANAGEMENT BASED ON SOCIAL COMPLEXITY}

Abstract: The parks are protected areas that represent a strategy of land management, regulating the dynamics of resource use and occupation of space. This assumes different identities, which increase the complexity of managing the parks, as can be seen from the perspective of different looks at multiple scales and values. This article aims at a theoretical and conceptual analysis on the process of social integration of parks, based on the extensive discussion of different authors with different backgrounds 
and views on the relations between parks and people. To this end, the text part of the conceptual discussion of the geographic space, its various dimensions and possible parallels with the concept of parks. It is argued that the constitution of space in a park, is a process emanating from the changing power relations, which influences its history and management of subjectivities and emotional limitations and administrative decisions. Then, it reinforces the idea that the management of these protected areas suffer from multi scale nature of the problems, as well as with the various values attributed to protected natural areas. Accordingly, the management council of the park is of great importance because it represents a bridge linking these different administrative scales. Thus, it confirms the need to know the set of perceptions about the park and its management as a way to address the complexity of their relations with society. We conclude that this broader view is important for conservation because it subsidizes a management that considers the human dimensions related to the parks.

Keywords: parks; protected areas; institutionalized spaces; management.

\section{BIBLIOGRAFIA}

ABAKERLI, S (2001(. A critique of development and conservation policies in environmentally sensitive regions in Brazil. Geoforum, v.32, p.551-556.

AGRAWAL, A.; GIBSON, C.C (1999). Enchantment and disenchantment: the role of community in natural resource conservation. World Development, v.27, n.4, p.629-649.

ALPERT, P (Nov. 1995). Applying ecological research at integrated conservation and development projects. Ecological Applications, v.5, n.4, p.1-5.

ANGERMEIER, P.L (Apr. 2000). The natural imperative for biological conservation. Conservation Biology, v.14, n.2, p.373-381.

BARBAULT, R. A (2006). conservação da biodiversidade: um desafio para a ecologia. In: GARAY, I.; BECKER, B.K. (Org). Dimensões Humanas da Biodiversidade: $\mathrm{O}$ desafio de novas relações sociedadenatureza no século XXI. Petrópolis: Vozes. p.381-399.

BAUER, M.W.; GASKELL, G (1999). Towards a paradigm for research on social representations. Journal for the Theory of Social Behavior, v.29, n.2, p.163-186. 
BENSUSAN, N (2006). Conservação da Biodiversidade em Áreas Protegidas. Rio de Janeiro: FGV. $176 \mathrm{p}$.

BERKES, F (2004). Rethinking community-based conservation. Conservation Biology, v.18, n.3, p.621-630.

BERTOLAS, R.J (Feb. 1998). Cross-cultural environmental perception of wilderness. Professional Geographer, v.50, n.1, p.98-111.

BRASIL (2002). Lei ${ }^{\circ} 9.985$, de 18 de julho de 2000. Decreto $n^{\circ} 4.940$, de 22 de Agosto de 2002. Institui o Sistema Nacional de Unidades de Conservação da Natureza SNUC. Brasília: IBAMA, Diretoria de Ecossistemas. $35 \mathrm{p}$.

BRIDGEWATER, P.B (2002). Biosphere reserves: special places for people and nature. Environmental Science and Policy, n.5, p.9-12.

BRUNCKHORST, D.J (2002). Institutions to sustain ecological and social systems. Ecological Management and Restoration, v.3, n.2, p.108-116.

CABRAL, L.O.; BUSS M.D (2002). A paisagem como campo de visibilidade e significação: um estudo de caso. Espaço e Cultura, n.13, p.47-62.

CASTRO, P (2003). Pensar a natureza e o ambiente - alguns contributos a partir da teoria das representações sociais. Estudos de Psicologia, v.8, n.2, p.263-271.

CORREAA, R. L (1005). Espaço, um conceito-chave da geografia. In: CASTRO, I.E.; GOMES, P.C.C.; CORRÊA, R.L. (Org.). Geografia: Conceitos e temas. Rio de Janeiro: Bertrand Brasil. p.15-47.

DIEGUES, A.C (2000). Etnoconservação da natureza: enfoques alternativos In: _. Etnoconservação: novos rumos para conservação da natureza. São Paulo: Hucitec. p. 1-46.

(2004). O mito moderno da natureza intocada. 5. ed. São Paulo: Hucitec; Núcleo de apoio à pesquisa sobre populações humanas e áreas úmidas brasileiras; USP. 169 p.

DOUROJEANNI, M.J.; PÁDUA, M.T.J (2007). Biodiversidade: a hora decisiva. 2. ed. Curitiba: Ed. Universidade Federal do Paraná. 284 p.

FALL, J.J (2003). Planning protected areas across boundaries: new paradigms and old ghosts. Journal of Sustainable Forestry, v.17, n.1-2, p.81-102.

FERREIRA, L.C (jan./jun. 2004). Dimensões humanas da biodiversidade: mudanças sociais e conflitos em torno de áreas 
protegidas no Vale do Ribeira, SP, Brasil. Ambiente e Sociedade, v.7, n.1, p.47-66.

FERREIRA, L. C.; CAMPOS, S. V.; CREADO, E. S. J.; MENDES, A. B. V.; CAROPRESO, C (jan/jun 2007). Encontro das Águas: Dinâmicas Sociais e Biodiversidade na Amazônia Brasileira. Revista Teoria \& Pesquisa, São Carlos, v.26, n. 1, p. 15-37.

GERHARDT, C.; ALMEIDA, J (jul./dez. 2005). A dialética dos campos sociais na interpretação da problemática ambiental: uma análise crítica a partir de diferentes leituras sobre os problemas ambientais. Ambiente $e$ Sociedade, v.8, n.2, p.1-31.

GODOY, A (2000). O modelo de Natureza e a natureza do modelo. São Paulo em Perspectiva, v.4, n.14, p.129-138.

GÖRG, C. The construction of societal relationships with nature. Poiesis Prax, v.3, p.22-36, Jun. 2004.

GRÖNING, G (2004). A questionabilidade do conceito de paisagem. Revista RA'E GA, n.8, p.9-18.

HOLZER, W (1999). O lugar na geografia humanista. Revista Território, n.7, p.67-78.

IBAMA (2002). Como o lbama exerce a educação ambiental. Brasilia. $32 \mathrm{p}$.

IBASE (2006). Educação ambiental em unidades de conservação. Rio de Janeiro. $28 \mathrm{p}$.

INFIELD, M (2001). Cultural values: A forgotten strategy for building community support for protected areas in Africa. Conservation Biology, v.15, n.3, p.800-802.

JEPSON, P.; CANNEY, S (2001). Biodiversity hotspots: hot for what? Global Ecology and Biogeography, n.10, p.225-227.

LITTLE, P.E (1999). Environments and environmentalisms in anthropological research: facing a new millennium. Annual Review of Anthropology, v.28, p.253-284.

LOUREIRO, C.F.B.; AZAZIEL, M.; FRANCA, N (2003). Educação ambiental e gestão participativa em unidades de conservação. 2. ed. Rio de Janeiro: IBAMA. 44 p.

LUTZENHISER, L (Mar. 2002). Environmental sociology: the very idea. Organization and Environment, v.15, n.1, p.5-9.

LYNAM, T. et al(2007). A review of tools for incorporating community knowledge, preferences and values into decision making in natural resources management. Ecology and Society, Waterloo, ON, v.12, n.1, 
2007. Article 5. Disponível em: <http://www.ecologyandsociety.org /vol12/iss1/art5/>. Acesso em: 30 out. 2007.

MAXIMIANO, L.A (2004). Considerações sobre o conceito de paisagem. Revista RA'E GA, n.8, p.83-91.

MEDEIROS, R (jan./jun. 2006). Evolução das tipologias e categorias de áreas protegidas no Brasil. Ambiente e Sociedade, v.9, p.41-64.

. IRVING, M.A.; GARAY, I (2006). Áreas protegidas no Brasil: Interpretando o contexto histórico para pensar a inclusão social. In: Áreas protegidas e inclusão social: Construindo novos significados. IRVING, M.A. (Org.). Rio de Janeiro: Fundação Bio-Rio - Núcleo de produção Editorial Aquarius. p.5-40.

MEINIG, D.W (2002). O olho que observa: dez versões da mesma cena. Espaço e Cultura, n.13, p.35-46.

MILANO, M.S (2002). Por que existem unidades de conservação. In: (Org). Unidades de conservação: Atualidades e tendências. Curitiba: Fundação O Boticário de Proteção a Natureza. p. 193-208.

MOREIRA, R (2002). O racional e o simbólico na geografia. In: Natureza e sociedade de hoje: Uma leitura geográfica. SOUZA M.A. et al. (Org.). 4. ed. São Paulo: HUCITEC - Associação Nacional de Pós Graduação e Pesquisa em Planejamento Urbano e Regional. p.46-55.

O'BRIEN, E.A (2003). Human values and their importance to the development of forestry policy in Britain: a literature review. Forestry, v.76, n.1, p.4-17.

ORMSBY, A.; KAPLIN, B.A (2005). A framework for understanding community resident perceptions of Masoala National Park, Madagascar. Environmental Conservation, v.32, n.2, p.156-164.

PAASI, A (2002). Bounded spaces in the mobile world: deconstructing "regional identity". Tijdschrift voor economishe en sociale geografie, v.2, p.137-148.

PEDLOWSKI, M.; DALE, V.; MATRICARDI, E (1999). A criação de áreas protegidas e os limites da conservação ambiental em Rondônia. Ambiente e Sociedade, v.2, n.5, p.93- 107.

PELUSO, M.L (2003). O potencial das representações sociais para a compreensão interdisciplinar da realidade: geografia e psicologia ambiental. Estudos de Psicologia, v.8, n.2, p.321-327. 
PIMENTEL, D.S.; SOUZA, J.P.; MAGRO, T.C (2009). Em busca de um conceito multidimensional de Unidade de Conservação. Revista Vozes em Diálogo, Rio de Janeiro, v.2, n.3, p. 1-17.

PIRES, J.S.R.; SANTOS, J.E.; PIRES, A.M.Z.C. R (2003). Aspectos conceituais para a gestão biorregional. In: BAGER, A. (Ed.). Áreas protegidas: conservação no âmbito do cone sul. Pelotas: Edição do editor. p.117-131.

PRIMACK, R.B.; RODRIGUES, E (2001). (Ed.). Biologia da conservação. Londrina: Edição dos Editores. 327 p.

REBORATTI, C.E (enero/jun. 2001). Una cuestión de escala: sociedad, ambiente, tiempo y território. Sociologias, v.3, n.5, p.80-93.

RODRIGUES, C.L (2001). Limites do consenso: territórios polissêmicos na Mata Atlântica e a gestão ambiental participativa. 2001. 254 p. Tese (Doutorado em Geografia Humana) - Faculdade de Filosofia e Ciências Humanas, Departamento de Geografia, Universidade de São Paulo, São Paulo.

RÖPER, M (1999). Geografia Social e Unidades de Conservação. Reflexões teóricas e exemplos da Bacia do Alto Paraguai. Geosul, v.14, n.27, p.45-66.

(2000). A difícil arte do planejamento participativo: A implementação da APA Estadual da Chapada dos Guimarães como exemplo de institucionalização territorial. In: CONGRESSO BRASILEIRO DE UNIDADES DEE CONSERVAÇÃO, 2, Campo Grande, 2000, Anais... Campo Grande, MS: Rede Nacional Pró-Unidade de Conservação; Fundação O Boticário de Proteção à Natureza, v. 2. p.69-78.

RYAN, R.L (2005). Exploring the effects of environmental experience on attachment to urban natural areas. Environment and behavior, v.37, n.1, p.3-42.

SCHWARTZMAN, S.; NEPSTAD, D.; MOREIRA, A (Oct. 2000). Arguing tropical forest conservation: People versus parks. Conservation Biology, v.14, n.5, p.1370-1374.

SOUZA, M. J. L (1995). O território: sobre espaço e poder, autonomia e desenvolvimento. In: Geografia: Conceitos e temas. CASTRO, I.E.; GOMES, P.C.C.; CORREAA, R.L. (Org.). Rio de Janeiro: Bertrand Brasil Ed. p.78-116.

STRINGER, L.C; DOUGILL, A.J.; FRASER, E.; HUBACEK, K.; PRELL, C.; REED, M.S. Unpacking "participation" in the adaptive management of social-ecological systems: a critical review. Ecology and 
Society, Waterloo, ON, v.11, n.2, 2006. Article 39. Disponível em: <http://www.ecologyandsociety.org/vol11/iss2/art39/>. Acesso em: 30 out. 2007.

TERBORGH, J.; VAN SCHAIK, C (2002). Por que o mundo necessita de parques? In: Terborgh, J.; van Schaik, C.; Davenport, L.; Rao M. (Org.). Tornando os parques eficientes: estratégias para a conservação da natureza nos trópicos. Curitiba: Universidade Federal do Paraná; Fundação O Boticário de Proteção à Natureza. cap. 1, p. 25-36.

TRUDGILL, S (2001). Psychobiogeography: meanings of nature and motivations for a democratized conservation ethic. Journal of Biogeography, v.28, p.677-698.

TUAN, Y (1980). Topofilia: um estudo da percepção, atitudes e valores do meio ambiente. São Paulo: Ed. DIFEL, Difusão Editorial. 288 p.

(1983). Espaço e lugar: a perspectiva da experiência. São Paulo: DIFEL, Difusão Editorial. 250 p.

VALLEJO, L.R (2002). Unidades de Conservação: uma discussão teórica à luz dos conceitos de território e de políticas públicas. GEOgraphia, n.8, p.77-106.

WADE-BENZONI, K.A.; LI, M.; THOMPSON, L.L.; BAZERMAN, M.H (2007). The malleability of environmentalism. Analyses of Social and Public Policy, v.7, n.1, p.1-27.

WAGNER, F.H (1996). Principles for conservation of wild living resources: another perspective. Ecological Applications, v.6, n.2, p.365-367.

WATSON, A.E (2000). Wilderness use in the year 2000: societal changes that influence human relationships with wilderness. USDA forest service proceedings $R M R S$, v.4, p.53-60.

WATSON, A.E.; LANDRES, P (1999). Changing wilderness values. In: CORDELL, H. K. (Org.). Outdoor recreation in American life: a national assessment of demand and supply trends. Champaign, IL: Sagamore. p.384-388.

WEST, P.; IGOE, J.; BROCKINGTON, D (2006). Parks and people: the social impact of protected areas. Annual Review of Anthropology, v.35, p.251-277.

YOUNÉS, T.; GARAY, I (2006). As dimensões humanas da biodiversidade: o imperativo das abordagens integrativas. In: GARAY, I.; BECKER, B.K. (Org). Dimensões Humanas da Biodiversidade: O desafio de novas relações sociedade-natureza no século XXI. Petrópolis: Ed. Vozes. p.57-72. 